\title{
Are patients with panic disorder respiratory subtype more vulnerable to tobacco, alcohol or illicit drug use?
}

\section{Pacientes com subtipo respiratório do transtorno de pânico são mais vulneráveis ao uso de tabaco, álcool ou outras substâncias?}

\author{
Rafael C. Freire ${ }^{1}$, Antonio E. Nardi ${ }^{1}$ \\ 1 Laboratory of Panic and Respiration, Institute of Psychiatry, Federal University of Rio de Janeiro, National Institute for Translational Medicine (INCT-TM), Rio de Janeiro, Brazil.
} Institution where the study was conducted: Laboratory of Panic and Respiration, Institute of Psychiatry, Federal University of Rio de Janeiro, National Institute for Translational Medicine (INCT-TM), Rio de Janeiro, Brazil.

Received: 6/13/2012 - Accepted: 4/29/2013

\begin{abstract}
Background: Studies have documented high use of tobacco, alcohol and illicit drugs in patients with panic disorder (PD). The comorbid substance use disorders worsen the prognosis of mood and anxiety disorders. The respiratory subtype (RS) of PD seems to represent a more severe and distinct form of this disorder associated with higher familial history of PD and more comorbidity with other anxiety disorders. Objectives: Describe the patterns of tobacco, alcohol or illicit drug use in PD patients, and also to ascertain if patients with the RS use these substances more than those of the non-respiratory subtype. Methods: This is a cross-sectional study with 71 PD patients. The Alcohol Use Disorders Identification Test and Fagerstrom Tobacco Questionnaire were used in the evaluation. Patients with four or five respiratory symptoms were classified in the RS, the remaining patients were classified as non-respiratory subtype. Results: In our sample $31.0 \%$ were smokers, $11.3 \%$ were hazardous alcohol users and none of them was using illicit drugs. There were no differences between the respiratory and non-respiratory subtypes regarding the use of tobacco, alcohol, cannabis, cocaine, stimulants and hallucinogens. Discussion: The RS was not correlated to the use of tobacco, alcohol and illicit drugs. Additional epidemiological and clinical studies focusing the relationship between PD and substance use are warranted.
\end{abstract}

Freire RC, Nardi AE / Rev Psiq Clín. 2013;40(4):135-8

Keywords: Panic disorder, agoraphobia, respiratory subtype, smoking, substance-related disorders.

\section{Resumo}

Contexto: Estudos anteriores têm mostrado associações entre o transtorno de pânico (TP) e o uso de tabaco, álcool e substâncias ilícitas. É conhecido que transtornos de uso de substâncias interferem negativamente no prognóstico de transtornos de ansiedade e depressão. No subtipo respiratório (SR) do TP há mais história familiar de TP e maior risco de comorbidades com transtornos de ansiedade. Objetivos: Descrever os padrões de uso de tabaco, álcool e outras substâncias em pacientes com TP. Além disso, analisar se pacientes do SR usam mais essas substâncias do que os pacientes do subtipo não respiratório. Métodos: Esse foi um estudo transversal com 71 pacientes com TP. As escalas Alcohol Use Disorders Identification Test e Fagerstrom Tobacco Questionnaire foram aplicadas. Pacientes com quatro ou cinco sintomas respiratórios foram considerados no SR, e os demais pacientes foram considerados como do subtipo não respiratório. Resultados: Na amostra estudada, 31,0\% dos pacientes eram fumantes, 11,3\% faziam uso perigoso de álcool e nenhum fazia uso de substâncias ilícitas. Não houve diferença entre os subtipos respiratório e não respiratório em relação a tabagismo, uso de álcool, cannabis, cocaína, estimulantes e alucinógenos. Conclusão: O SR não foi correlacionado com o uso de tabaco, álcool ou drogas ilícitas. Mais estudos clínicos e epidemiológicos focando a relação entre o TP e uso de substâncias são necessários.

Freire RC, Nardi AE / Rev Psiq Clín. 2013;40(4):135-8

Palavras-chave: Transtorno de pânico, agorafobia, subtipo respiratório, tabagismo, transtornos relacionados ao uso de substâncias.

\section{Introduction}

In the Diagnostic and Statistical Manual of Mental Disorders (DSM-IV)1, psychiatric diagnoses are based on clusters of symptoms and on characteristics of clinical course rather than on concurrent neurobiological mechanisms that are associated with these syndromes. According to this classification system, panic disorder (PD) is a unitary diagnostic category ${ }^{1}$. Nevertheless, within this category there are diverse clinical presentations, leading to concerns that PD is not a singular diagnosis ${ }^{2}$. As a response to these concerns, alternative classification schemes have been devised ${ }^{2}$. Several studies indicated that PD patients with prominent respiratory symptoms may represent a distinct subtype of this disorder ${ }^{3}$. High rates of alcohol ${ }^{4}$ and cigarette $^{5}$ use have been found in respiratory subtype patients. The use of cannabis 6 , stimulants, cocaine and hallucinogens ${ }^{7}$ has been correlated to PD but the association between the respiratory subtype and the use of these substances has never been investigated.
There is scientific evidence that the "respiratory symptoms" group is a distinct PD subtype ${ }^{3,8}$. Briggs et al. ${ }^{8}$ studied the descriptions of the most recent severe panic attack of $1108 \mathrm{PD}$ patients and performed a principal component analysis of the symptoms. The symptoms of fear of dying, chest pain/discomfort, shortness of breath, paresthesias, and sensation of choking defined a distinct group and the absence of these symptoms defined another group. Patients were included in the respiratory subtype group if they had four or five of these respiratory symptoms during the PA; patients with three or less of these symptoms belonged to the non-respiratory subtype. The group with prominent respiratory symptoms suffered more spontaneous PAs, whereas patients in the non-respiratory subtype depicted more situational PAs8.

Recent studies indicate that respiratory subtype patients may have higher familial history of PD, lower neuroticism scores, and higher scores in severity scales compared to non-respiratory subtype patients ${ }^{3,9}$. Roberson-Nay et al. ${ }^{10}$ studied the PD respiratory subtype 
in an epidemiologic sample $(\mathrm{n}=2294)$ and a clinical sample $(\mathrm{n}=$ 1169) and found high temporal stability for the subtype. The authors also found higher comorbidity with agoraphobia, social anxiety disorder, generalized anxiety disorder and specific phobia for the respiratory subtype, compared to the non-respiratory subtype ${ }^{10}$. In two studies with smaller samples ${ }^{11,12}$ the respiratory subtype was associated with low comorbidity with major depressive disorder, but in the study of Roberson-Nay et al. ${ }^{10}$ the opposite was found. There were also conflicting findings regarding the duration of the illness ${ }^{5,10}$. High prevalence of respiratory symptoms was found in patients with nocturnal PAs or traumatic suffocation history3.

There is a high occurence of smoking in patients with anxiety and depressive disorders ${ }^{13,14}$. Compared to patients with other psychiatric disorders, or even with people without psychiatric disorders, a higher proportion of PD patients smoke cigarettes ${ }^{15}$. The temporal pattern underlying such a co-occurrence is still a matter of debate. Clinical and experimental data suggested that smoking increases the risk of new onset $\mathrm{PD}$, but it is also possible that $\mathrm{PD}$ precedes smoking. There are five different hypotheses to explain the relationship between PD and smoking: (a) cigarette smoking may lead to the onset of panic by inducing respiratory abnormalities or lung disease - smoking may increase the risk of panic because, according to the false suffocation alarm theory, it induces an overreaction to suffocation signals; (b) nicotine may produce physiologic effects characteristic of panic attacks by promoting the release of norepinephrine into the brainstem; (c) smoking may modify the expression of panic disorder by increasing potentially fear-producing bodily sensations - individuals with panic disorder who usually perceive themselves as being physically unhealthy would more likely react with exaggerated anxiety; (d) panic disorder patients may smoke as a means of self-medicating their symptoms, because of the anxiolytic effects of nicotine or because of cognitive mechanisms (smoking narrows the focus of attention and diverts one from stressful cognitions). Through this pathway, PD would increase the risk of smoking; (e) the co-ocurrance of smoking and PD suggest the two problems may share a common vulnerability such as neuroticism or other personality features ${ }^{15}$. Respiratory abnormalities are present in both smokers and PD patients ${ }^{16}$, and they are more frequent in the respiratory subtype ${ }^{3}$ suggesting there may be an association between smoking and the respiratory subtype. Biber and Alkin ${ }^{5}$ found a higher proportion of smokers and higher cigarette consumption in the respiratory subtype patients compared to the non-respiratory subtype.

Concerning the consumption of alcohol, several studies indicate there is an association between alcohol use disorders and $\mathrm{PD}^{17}$. $\mathrm{Pa}$ nic patients may use alcohol as self-medication, while in alcoholics alcohol withdrawal may trigger the onset of PD, explaining the frequent comorbidity between these two disorders ${ }^{7}$. Lifetime marijuana use was correlated to current and lifetime diagnosis of PD'. Although the relationship between cannabis use and PD is not fully understood investigators believe that marijuana may be used as an attempt of self-medication ${ }^{6}$. Sareen et al. ${ }^{7}$ found in anxiety disorder patients higher lifetime rates of stimulant, cocaine, hallucinogen and heroin use. PD was correlated to the use of stimulants, cocaine and hallucinogens, with the highest odds ratio for hallucinogens (3.02 to 3.62). It is not clear whether there is a causal relationship between the use of these illicit drugs and PD or not 7 . Studies regarding the effects of marijuana smoking in pulmonary function yield to conflicting results, but the heavy use of marijuana probably decreases pulmonary function ${ }^{18}$. There are also conflicting results concerning the effects long-term use of free-base cocaine on respiration ${ }^{19,20}$. There are no studies indicating that the use of alcohol, stimulants and hallucinogens produce respiratory abnormalities. Although the use of these substances is associated to PD it is probably not associated to the respiratory subtype of PD.

The aim of this study is to describe the patterns of tobacco, alcohol or illicit drug use in PD patients. The secondary objective is to verify if the respiratory subtype patients use more of these substances than those in the non-respiratory subtype.

\section{Methods}

General practitioners in public clinics and hospitals in Rio de Janeiro usually refer PD patients to the LABPR for psychiatric treatment. When patients arrived for the first consultation with the psychiatrist, they were invited to participate in the current study. Treatment was offered to all patients without any cost, regardless the agreement to participate in the study.

The present study consists of a cross-sectional study of PD patients, with ages between 18 and 65. Subjects were enrolled in the study's protocol in their first visit to the Laboratory of Panic and Respiration (LABPR) of the Institute of Psychiatry of the Federal University of Rio de Janeiro. In this evaluation diagnoses were made according to the Mini International Neuropsychiatric Interview 5.0 (MINI) ${ }^{21,22}$ and all patients fulfilled DSM-IV ${ }^{1}$ criteria for PD. The diagnoses of comorbid psychiatric disorders, substance abuse, or dependence according to the criteria from the MINI were also registered. Clinicians rated the Clinical Global Impression (CGI) ${ }^{23}$ and registered the respiratory symptoms in the most recent severe panic attack. Patients with four or five respiratory symptoms were classified in the respiratory subtype, the remaining patients were classified as non-respiratory subtype. All subjects filled up a form with sociodemographic and clinical data including age, gender, education, occupation, familial history of PD and age of onset of PD. Subjects were asked if they were currently using or used tobacco, alcohol or any illicit drug in the past. Subjects were also asked if the onset of smoking preceded PD and if there has been an overlap of PD and smoking. All subjects filled the Alcohol Use Disorders Identification Test (AUDIT) ${ }^{24}$ and smokers filled the Fagerström Test for Nicotine Dependence (FTND) ${ }^{25}$, both validated to Brazilian Portuguese 26,27 . Scores of 8 and higher in the AUDIT were considered hazardous alcohol use ${ }^{24}$.

All PD patients were submitted to a complete medical evaluation, and those with unstable medical condition, pregnancy, suicide risk, bipolar disorder, schizophrenia, delusional or psychotic disorders, organic brain syndrome, severe personality disorder or epilepsy were not included in the sample.

The local Ethics Committee approved the protocol for this study and all patients signed an informed consent before participating in the study.

The respiratory subtype patients were compared to the non-respiratory subtype patients. The Student's t test was used to compare means of continuous variables between two groups. For categorical variables the comparison was made with the chi-square. All analyses were two-tailed and the level of statistical significance was set at 5\%.

\section{Results}

In the sample, there were 71 patients, $67.6 \%(n=48)$ females and $32.4 \%(\mathrm{n}=23)$ males, the mean age was $39.3(\mathrm{SD}=10.6)$ years. The mean income was $4.9(\mathrm{SD}=3.3)$ minimum wages, $70.4 \%(\mathrm{n}=50)$ were employed, $29.6 \%(n=21)$ had family history of PD and the mean age of onset was $33.1(\mathrm{SD}=10.2)$ years. The most frequent comorbid diagnosis was agoraphobia $(71.8 \%, \mathrm{n}=51)$, followed by major depressive disorder $(45.1 \%, \mathrm{n}=32)$, generalized anxiety disor$\operatorname{der}(7.0 \%, \mathrm{n}=5)$, social anxiety disorder $(1.4 \%, \mathrm{n}=1)$ and obsessive compulsive disorder $(1.4 \%, \mathrm{n}=1)$. The prevalence of RS was $57.7 \%$ $(\mathrm{n}=41)$ and the mean CGI score was $4.3(\mathrm{SD}=0.9)$.

There were $31.0 \%(n=22)$ smokers and their mean Fagerstrom Tobacco Questionnaire score was 5.6 ( $\mathrm{SD}=2.7)$. The AUDIT scores were low (mean $=2.4, \mathrm{SD}=3.9)$ and only $31.0 \%(\mathrm{n}=22)$ of the patients reported drinking alcoholic beverages more than once a month. Eight (11.3\%) patients had AUDIT score above 7, indicating hazardous alcohol use. Three patients (4.2\%) fulfilled criteria for substance dependence in 12 months, and there were no other substance use disorder diagnoses. One patient was diagnosed with stimulant dependence but she stopped taking this substance six months before the evaluation. The other two patients were alcohol dependent with high AUDIT scores (12 and 19). There was a small 
prevalence of lifetime use of stimulants $(1.4 \%, \mathrm{n}=1)$, cocaine $(5.6 \%$, $\mathrm{n}=4)$, cannabis $(11.3 \%, \mathrm{n}=8)$ and hallucinogens $(1.4 \%, \mathrm{n}=1)$, but none of the patients were using these substances in the moment of the evaluation.

Regarding the timing of smoking and PD, all lifetime smokers $(46.5 \%, \mathrm{n}=33)$ reported that smoking came first. Among lifetime smokers $66.7 \%(\mathrm{n}=22)$ were currently smoking, $24.2 \%(\mathrm{n}=8)$ stopped smoking and reported no overlap between smoking and PD, 9.1\% $(n=3)$ stopped smoking and reported a period of overlap between smoking and PD. Among females 35.4\% were current smokers while among males there were $21.7 \%$ of smokers, but this difference was not statistically significant.

In the comparison between the respiratory and non-respiratory subtype patients there were few differences. Only $26.8 \%(\mathrm{n}=11)$ of the RS patients and $36.7 \%(\mathrm{n}=11)$ of the non-respiratory subtype reported drinking alcoholic beverages more than once a month, but this difference did not show statistical significance. The respiratory subtype patients had lower employment rates (Chi-square $=4.157$, $1 \mathrm{df}, \mathrm{P}=0.041$ ), more comorbid generalized anxiety disorder (Chi-square $=3.936,1 \mathrm{df}, \mathrm{P}=0.047$ ) and higher CGI scores ( $\mathrm{t}$ test, $\mathrm{P}=$ $0.004)$ compared to the non-respiratory subtype. There was also a trend (Chi-square $=3.672,1 \mathrm{df}, \mathrm{P}=0.055$ ) towards higher lifetime illicit drug use in the non-respiratory subtype, compared to the respiratory subtype (Table 1 ). There were no statistically significant differences between the two subtypes regarding the use of tobacco or alcohol.

Table 1. Comparison between respiratory and non-respiratory subtypes

\begin{tabular}{|c|c|c|c|c|}
\hline & \multicolumn{2}{|c|}{ Non-respiratory subtype } & \multicolumn{2}{|c|}{ Respiratory subtype } \\
\hline & mean/n & $\mathrm{SD} / \%$ & mean/n & $\mathrm{SD} / \%$ \\
\hline \multicolumn{5}{|l|}{ Gender } \\
\hline Male & 10 & 33.3 & 13 & 31.7 \\
\hline Female & 20 & 66.7 & 28 & 68.3 \\
\hline Age & 39.5 & 11.6 & 39.2 & 10.1 \\
\hline Employeda & 25 & 83.3 & 25 & 61.0 \\
\hline Agoraphobia & 19 & 63.3 & 32 & 78.0 \\
\hline MDD & 12 & 40.0 & 20 & 48.8 \\
\hline GADb & 0 & 0 & 5 & 12.2 \\
\hline Alcohol dependence* & 1 & 3.3 & 1 & 2.4 \\
\hline Stimulant dependence* & 0 & 0 & 1 & 2.4 \\
\hline CGIc & 3.9 & 0.8 & 4.5 & 0.8 \\
\hline \multicolumn{5}{|l|}{ Current substance use } \\
\hline Smoking & 9 & 30.0 & 13 & 31.7 \\
\hline FTND** & 6.3 & 2.1 & 5.1 & 3.0 \\
\hline AUDIT score & 2.7 & 4.5 & 2.2 & 3.4 \\
\hline Hazardous alcohol use $e^{* * *}$ & 5 & 16.7 & 3 & 7.3 \\
\hline \multicolumn{5}{|l|}{ Lifetime substance use } \\
\hline Smoking & 14 & 46.7 & 19 & 46.3 \\
\hline Alcohol**** & 9 & 30.0 & 12 & 29.3 \\
\hline \begin{tabular}{|lll} 
Ilicit drugs \\
\end{tabular} & 7 & 23.3 & 3 & 7.3 \\
\hline Cocaine & 3 & 10.0 & 1 & 2.4 \\
\hline Cannabis & 5 & 16.7 & 3 & 7.3 \\
\hline
\end{tabular}

SD: standard deviation; PD: panic disorder; MDD: major depressive disorder; GAD: generalized anxiety disorder; CGI: Clinical Global Impression (state); FTND: Fagerstrom Tobacco Questionnaire; AUDIT: Alcohol Use Disorders Identification Test.

* Substance dependence in 12 months according to the MINI.

** Among smokers only.

*** Score of 8 or more in the AUDIT.

**** Several times a week.

a Chi-square $=4.157,1 \mathrm{df}, \mathrm{P}=0.041$.

b Chi-square $=3.936,1 \mathrm{df}, \mathrm{P}=0.047$.

c Student's t test, $\mathrm{P}=0.004$

d Chi-square $=3.672,1 \mathrm{df}, P=0.055$.

\section{Discussion}

The use of tobacco among PD patients was high, but the use of alcohol and illicit drugs were low. Compared to the non-respiratory, respiratory subtype patients had lower employment rates, higher comorbidity with GAD, higher CGI scores and there was a trend towards lower lifetime use of illicit drugs. There were no differences between the two groups regarding the use of tobacco, alcohol, cocaine, cannabis, stimulants and hallucinogens.

In the Brazilian population $17.2 \%$ are current smokers and $35.3 \%$ are lifetime smokers ${ }^{28}$, while in PD patients $31.0 \%$ were current smokers and $46.5 \%$ were lifetime smokers. The high proportion of smokers among PD patients corroborates the evidences indicating an association between PD and smoking. However, the present study did not show a correlation between smoking and the respiratory subtype. There were no differences regarding the prevalence of current or lifetime smoking. The degree of nicotine dependence was also similar between the two groups. In the study from Biber and Alkin ${ }^{5}$ the respiratory subtype was associated with current smoking and high cigarette consumption (pack year). The differences in the findings of these two studies may be due to the smaller sample size and to the fact that patients with current or past depression were not included in Biber and Alkin's study ${ }^{5}$. As in most studies exploring the relationship between PD and smoking ${ }^{15}$, smoking preceded PD in all lifetime smokers. There is not sufficient data to rule out the possibility that the cumulative effect of smoking increases the risk of the PD respiratory subtype.

It was estimated that $42 \%$ of the Brazilian population consumes alcoholic beverages at least once a month, while $58 \%$ consumes alcohol less than once a month ${ }^{29}$. A recent study ${ }^{30}$ indicated that $24.6 \%$ of women consume alcohol during pregnancy, increasing the risk of malformations and other problems. Alcohol use is also associated with an increased risk of traffic accidents ${ }^{31}$. In a study conducted in Brazil, 20\% of the drivers had high alcohol levels in the breathanalyzer test and $66 \%$ of them reported driving under the effect of alcohol at least once ${ }^{31}$. In our study, few PD patients were using alcohol, the mean AUDIT score was low and only $2.8 \%$ of the patients were alcohol-dependent. Sbrana et al. ${ }^{32}$ also found low rates of alcohol use disorders in a clinical sample of PD patients, with a prevalence of $4 \%$. On the other hand, several studies indicate that among alcohol-dependent patients the rate of $\mathrm{PD}$ is high, ranging from $13 \%$ to $25 \%{ }^{17}$. The current study did not replicate the results of our previous work 4 in which the respiratory subtype was correlated to previous alcohol use. More studies are needed to explore the relationship between alcohol use and the respiratory subtype.

Despite the literature indicating high lifetime illicit drug use in PD patients, in the current study these rates were low. Previous studies indicated that lifetime marijuana use increased the risk for panic attacks and PD, also more than a half of the patients with 12-month PD were lifetime marijuana users ${ }^{6,33}$. Sareen et al. ${ }^{7}$ also found rates much higher than those found in the present study, with lifetime prevalences of $2.8 \%-14.9 \%$ for stimulants, $4.1 \%-16.2 \%$ for cocaine, $6.9 \%-10.7 \%$ for hallucinogens and $0.4 \%-1.4 \%$ for heroin in anxiety disorder patients. The current study was the first one to explore the possible association between illicit drug use and the respiratory subtype, and no correlations were found.

The high mean age and the preponderance of females in our sample may explain why the rates of alcohol and illicit drug use were low. In a sample with a majority of females one might expect a low rate of smokers, but female subjects with PD seem to smoke the same or more than males with $\mathrm{PD}^{14}$.

The main limitations of this study were the small sample size and a possible selection bias. The small sample size led to a low power in the statistical tests, increasing the risk of type II errors. In the Institute of Psychiatry of the Federal University of Rio de Janeiro, patients with a primary problem of substance abuse or dependence are usually referred to the Drug Abuse Research and Care Program (Programa de Estudos e Assistência ao Uso Indevido de Drogas PROJAD), which is a treatment center for substance use disorders. 
On the other hand, patients with primary anxiety and depression are usually referred to the Laboratory of Panic and Respiration. Other limitations of this study were that the age of onset and pack years were not registered, therefore the cumulative effect of smoking could not be assessed. The evaluation of alcohol and illicit drug use was also superficial. The authors used only the AUDIT scale to rate the alcohol use intensity, no scales for illicit drugs were employed. Age of onset, biomarkers and other variables regarding substance use were not registered.

In a clinical sample of PD patients, the prevalence of smoking was high and the use of alcohol and illicit drugs was low. The use of tobacco, alcohol, cannabis, cocaine, stimulants and hallucinogens were not correlated to the respiratory subtype of PD. Additional epidemiological and clinical studies focusing the relationship between PD and the use of tobacco, alcohol and illicit drugs are warranted.

\section{Acknowledgements}

Funding for this study was provided by the Brazilian Council for Scientific and Technological Development (CNPq), the Coordination for the Improvement of Higher Education Personnel (Capes) and the Carlos Chagas Filho Research Support Foundation of the State of Rio de Janeiro (Faperj).

\section{References}

1. APA. Diagnostic and Statistical Manual for Mental Disorders, 4 th edition (DSM-IV). 4 ed. Washington, DC: American Psychiatric Press; 1994.

2. Beck JG, Shipherd JC, Ohtake P. Do panic symptom profiles influence response to a hypoxic challenge in patients with panic disorder? A preliminary report. Psychosom Med. 2000;62(5):678-83.

3. Freire RC, Perna G, Nardi AE. Panic disorder respiratory subtype: psychopathology, laboratory challenge tests, and response to treatment. Harv Rev Psychiatry. 2010;18(4):220-9.

4. Freire RC, Lopes FL, Valença AM, Nascimento I, Veras AB, Mezzasalma $\mathrm{MA}$, et al. Panic disorder respiratory subtype: a comparison between responses to hyperventilation and $\mathrm{CO}(2)$ challenge tests. Psychiatry Res. 2008;157(1-3):307-10.

5. Biber B, Alkin T. Panic disorder subtypes: differential responses to $\mathrm{CO} 2$ challenge. Am J Psychiatry. 1999;156(5):739-44.

6. Zvolensky MJ, Cougle JR, Johnson KA, Bonn-Miller MO, Bernstein A. Marijuana use and panic psychopathology among a representative sample of adults. Exp Clin Psychopharmacol. 2010;18(2):129-34.

7. Sareen J, Chartier M, Paulus MP, Stein MB. Illicit drug use and anxiety disorders: findings from two community surveys. Psychiatry Res. 2006;142(1):11-7.

8. Briggs AC, Stretch DD, Brandon S. Subtyping of panic disorder by symptom profile. Br J Psychiatry. 1993;163:201-9.

9. Onur E, Alkin T, Tural U. Panic disorder subtypes: further clinical differences. Depress Anxiety. 2007;24(7):479-86.

10. Roberson-Nay R, Latendresse SJ, Kendler KS. A latent class approach to the external validation of respiratory and non-respiratory panic subtypes. Psychol Med. 2012;42(3):461-74.

11. Nardi AE, Nascimento I, Valença AM, Lopes FL, Mezzasalma MA, Zin WA, et al. Respiratory panic disorder subtype: acute and long-term response to nortriptyline, a noradrenergic tricyclic antidepressant. Psychiatry Res. 2003;120(3):283-93.

12. Nardi AE, Valença AM, Nascimento I, Lopes FL, Mezzasalma MA, Freire $\mathrm{RC}$, et al. A three-year follow-up study of patients with the respiratory subtype of panic disorder after treatment with clonazepam. Psychiatry Res. 2005;137(1-2):61-70.
13. Lopes FL, Nascimento I, Zin WA, Valença AM, Mezzasalma MA, Figueira I, et al. Smoking and psychiatric disorders: a comorbidity survey. Braz J Med Biol Res. 2002;35(8):961-7.

14. Freire RC, Mezzasalma MA, Valença AM, De-Melo-Neto VL, Lopes FL, Nascimento I, et al. Smoking and panic disorder: severity and comorbidities. Rev Psiquiatr Rio Gd Sul. 2007;29(3):281-5.

15. Cosci F, Knuts IJ, Abrams K, Griez EJ, Schruers KR. Cigarette smoking and panic: a critical review of the literature. J Clin Psychiatry. 2010;71(5):606-15.

16. Caldirola D, Bellodi L, Caumo A, Migliarese G, Perna G. Approximate entropy of respiratory patterns in panic disorder. Am J Psychiatry. 2004;161(1):79-87.

17. Cosci F, Schruers KR, Abrams K, Griez EJ. Alcohol use disorders and panic disorder: a review of the evidence of a direct relationship. J Clin Psychiatry. 2007;68(6):874-80.

18. Pletcher MJ, Vittinghoff E, Kalhan R, Richman J, Safford M, Sidney S, et al. Association between marijuana exposure and pulmonary function over 20 years. JAMA. 2012;307(2):173-81.

19. Marques-Magallanes JA, Koyal SN, Cooper CB, Kleerup EC, Tashkin DP. Impact of habitual cocaine smoking on the physiologic response to maximum exercise. Chest. 1997;112(4):1008-16.

20. Susskind H, Weber DA, Volkow ND, Hitzemann R. Increased lung permeability following long-term use of free-base cocaine (crack). Chest 1991;100(4):903-9.

21. Amorim P. Mini International Neuropsychiatric Interview (M.I.N.I.) desenvolvimento e validação de entrevista diagnóstica breve para avaliação dos Transtornos Mentais. Rev Bras Psiquiatr. 2000;22(3):106-15.

22. Sheehan DV, Lecrubier Y, Sheehan KH, Amorim P, Janavs J, Weiller E, et al. The Mini-International Neuropsychiatric Interview (M.I.N.I.): the development and validation of a structured diagnostic psychiatric interview for DSM-IV and ICD-10. J Clin Psychiatry. 1998;59(Suppl 20):22-33.

23. Guy W. ECDEU Assessment manual for psychopharmacology, revised. Rockville: National Institute of Mental Health; Dept. of Health, Education, and Welfare Publication; 1976.

24. Babor TF, Higgins-Biddle JC, Saunders JB, Monteiro MG. AUDIT - The Alcohol Use Disorders Identification Test: Guidelines for Use in Primary Care. 2nd ed. Geneva: World Health Organization; 2001.

25. Fagerstrom KO. Measuring degree of physical dependence to tobacco smoking with reference to individualization of treatment. Addict Behav. 1978;3(3-4):235-41.

26. Mendez BE. Uma versão brasileira do AUDIT - Alcohol Use Disorders Identification Test. Pelotas: Universidade Federal de Pelotas; 1999.

27. Carmo JT, Pueyo AA. A adaptaçäo ao português do Fagerström test for nicotine dependence (FTND) para avaliar a dependência e tolerância à nicotina em fumantes brasileiros. Rev Bras Med. 2002;59(1/2):73-80.

28. IBGE. Pesquisa Nacional por Amostra de Domicílios: Tabagismo 2008. Rio de Janeiro: IBGE; 2009.

29. Laranjeira R, Pinsky I, Zaleski M, Caetano R. I Levantamento nacional sobre os padrões de consumo de álcool na população brasileira. Brasília: Secretaria Nacional Antidrogas; 2007.

30. Silva CS, Ronzani TM, Furtado EF, Aliane PP, Moreira-Almeida A. Relationship between religious practice, alcohol use, and psychiatric disorders among pregnant women. Rev Psiq Clín. 2010;37(4):152-6.

31. Campos VR, Salgado R, Rocha MC, Duailibi S, Laranjeira R. Drinking and driving: characteristics of drivers with positive breathalyzer. Rev Psiq Clín. 2012;39(5):166-71.

32. Sbrana A, Bizzarri JV, Rucci P, Gonnelli C, Doria MR, Spagnolli S, et al. The spectrum of substance use in mood and anxiety disorders. Compr Psychiatry. 2005;46(1):6-13.

33. Zvolensky MJ, Lewinsohn P, Bernstein A, Schmidt NB, Buckner JD, Seeley $\mathrm{J}$, et al. Prospective associations between cannabis use, abuse, and dependence and panic attacks and disorder. J Psychiatr Res. 2008;42(12):1017-23. 